\title{
miR-155 functions downstream of angiotensin II receptor subtype 1 and calcineurin to regulate cardiac hypertrophy
}

\author{
YONG YANG ${ }^{1}$, YONG ZHOU ${ }^{2}$, ZHENG CAO $^{1}$, XIN ZHU TONG ${ }^{1}$, HUA QIANG XIE $^{1}$, \\ TAO LUO ${ }^{1}$, XIAN PING HUA ${ }^{3}$ and HAN QIN WANG ${ }^{4}$
}

\begin{abstract}
Departments of ${ }^{1}$ Cardiology and ${ }^{2}$ Medical Oncology, Taihe Hospital, Hubei University of Medicine, Shiyan, Hubei 442000; ${ }^{3}$ Department of Cardiology, Suizhou Central Hospital, Hubei University of Medicine, Suizhou, Hubei 441300;

${ }^{4}$ Institute of Basic Medical Sciences, Hubei University of Medicine, Shiyan, Hubei 442000, P.R. China
\end{abstract}

Received March 22, 2015; Accepted June 6, 2016

DOI: $10.3892 /$ etm.2016.3506

\begin{abstract}
Cardiac hypertrophy is characterized by maladaptive tissue remodeling that may lead to heart failure or sudden death. MicroRNAs (miRs) are negative regulators of angiotensin II and the angiotensin II receptor subtype $1\left(\mathrm{AGTR}_{1}\right)$, which are two components involved in cardiac hypertrophy. In the present study, the interaction between angiotensin II receptor subtype $1\left(\mathrm{AGTR}_{1}\right)$ signaling and miR-155 was investigated. Rat H9C2 (2-1) cardiomyocytes were transfected with miR-155 analogues or inhibitors, then stimulated with angiotensin II to induce cardiac hypertrophy. miR-155 expression was revealed to be altered following transfection with chemically-modified miR-155 analogues and inhibitors in rat cardiomyocytes. In cell cardiac hypertrophy models, the cell surface area, $\mathrm{AGTR}_{1}$, atrial natriuretic peptide and myosin heavy chain- $\beta$ mRNA expression levels were revealed to be lower in cells stimulated with miR-155 analogue-transfected cells treated with angiotensin II compared with cells stimulated with angiotensin alone $(\mathrm{P}<0.05)$, as determined using reverse transcription-polymerase chain reaction (PCR), quantitative PCR and western blot analyses. Furthermore, calcineurin mRNA and protein, intracellular free calcium and nuclear factor of activated T-cells-4 proteins were downregulated in miR-155 analogue-transfected cells treated with angiotensin II, as compared with cells stimulated with angiotensin II alone $(\mathrm{P}<0.05)$. In conclusion, the current study indicates that miR-155 may improve cardiac hypertrophy by downregulating $\mathrm{AGTR}_{1}$ and suppressing the calcium signaling pathways activated by $\mathrm{AGTR}_{1}$.
\end{abstract}

Correspondence to: Professor Zheng Cao, Department of Cardiology, Taihe Hospital, Hubei University of Medicine, 32 South Renmin Road, Shiyan, Hubei 442000, P.R. China

E-mail: caozheng908@163.com

Key words: microRNA-155, cardiac hypertrophy, angiotensin II receptor type 1

\section{Introduction}

Cardiac hypertrophy, the thickening of heart muscle, is a compensatory response to physical stimuli or pathological insults. These pathological remodeling responses are often accompanied by fibrosis, pump failure, myocyte degeneration and apoptosis, which may culminate in heart failure and sudden death (1). Heart failure occurs when the heart is unable to pump blood at a rate proportional to the body's requirement for oxygen, or when this function leads to cardiogenic pulmonary edema. With $>1$ million hospitalizations annually (up $175 \%$ in the past 25 years), and costs of $\sim \$ 15.4$ billion, acute heart failure is a critical health concern. Furthermore, half of the patients discharged from the hospital are readmitted within 6 months. In-hospital mortality rates remain high, between 4 and $7 \%(2,3)$. Heart failure is a significant problem as the population ages. The prevalence in the US is $2.5 \%$ of the population, or 5 million patients (3) Cardiac hypertrophy is a major determinant of congestive heart failure. Angiotensin II is known to participate in cardiac hypertrophy by binding to angiotensin II receptor subtype $1\left(\mathrm{AGTR}_{1}\right)$. In addition, AGTR $_{1}$ overexpression has been closely associated with cardiac hypertrophy (4).

MicroRNAs (miRs) are endogenous, highly conserved, small non-coding RNAs that negatively regulate the expression of target genes at the post-transcriptional level (5). miR-155 is encoded by the human miR-155 host gene and is abundantly expressed in the lungs, heart and kidneys (6). Seok et al (7) and Heymans et al (8) have revealed that gain-of-function mutations in miR-155 exacerbate myocardial hypertrophy, whereas loss-of-function mutations ameliorate cardiac hypertrophy. Sethupathy et al (9) experimentally investigated the target sites for hsa-miR-155 within the 3'-untranslated region of the human $A_{G T R}$ gene and demonstrated that hsa-miR-155 downregulated the expression of $\mathrm{AGTR}_{1}$. These previous findings suggest that miR-155 ameliorates hypertension by modulating $\mathrm{AGTR}_{1}$ expression, as $\mathrm{AGTR}_{1}$ signaling occurs upstream of cardiac hypertrophy (10). The present study therefore aimed to test the hypothesis that miR-155 promotes cardiac hypertrophy by targeting $\mathrm{AGTR}_{1}$, and to determine the underlying molecular behavior of miR-155 in cardiac hypertrophy. 


\section{Materials and methods}

Cell culture and reagents. Rat H9C2 (2-1) cardiomyocytes were purchased from the China Center for Type Culture Collection, Wuhan University (Wuhan, China). Lipofectamine 2000, TRIzol $^{\circledR}$ and Platinum SYBR ${ }^{\circledR}$ Green qPCR SuperMix-UDG were purchased from Invitrogen (Thermo Fisher Scientific, Inc., Waltham, MA, USA), angiotensin II was purchased from Sigma-Aldrich (St. Louis, MO, USA), and the mirVana PARIS RNA and Native Protein Purification kit was from Ambion (Thermo Fisher Scientific, Inc.). Rabbit anti-AGTR polyclonal antibody (cat. no. ab9391) was purchased from Abcam (Cambridge, UK). Rabbit anti-calcineurin- $\beta$ (CaN- $\beta$; cat. no. BS6114), nuclear factor of activated T-cells (NFAT-4; cat. no. BS1762) and glyceraldehyde-3-phosphate dehydrogenase (GAPDH; cat. no. BS60630) polyclonal antibodies were purchased from Bioworld Technology, Inc. (St. Louis Park, MN, USA). Goat anti-rabbit polyclonal antibody labeled with horseradish peroxidase (HRP) (cat. no. BA1125) were purchased from Boster Biological Technology, Co., Ltd., (Wuhan, China). miR-155 analogue and inhibitor, with or without fluorescein (FAM) conjugation, were synthesized by GenePharma (Shanghai, China), in accordance with the miR-155 sequence provided in the miRBase database (www. mirbase.org/; accession no. MIMAT0030409; 5'-UUAAUG CUAAUUGUGAUAGGGGU-3'). The sequences were as follows: miR-155 analogue forward, 5'-UUAAUGCUAAUU GUGAUAGGGGU-3' and reverse, 5'-CCCUAUCACAAU UAGCAUUAAUU-3'; and miR-155, 5'-ACCCCUAUCACA AUUAGCAUUAA-3'. The analogues and inhibitor were diluted with sterile water to a final concentration of $20 \mu \mathrm{mol} / 1$ and stored at $-80^{\circ} \mathrm{C}$ until use.

miR-155 transfection. Rat cardiomyocytes were seeded into 6 -well plates at a density of $1 \times 10^{8}$ cells $/ \mathrm{ml}$ in Dulbecco's modified Eagle's medium supplemented with $10 \%$ fetal bovine serum (Gibco; Thermo Fisher Scientific, Inc.). Cells were incubated at $37^{\circ} \mathrm{C}$ and $5 \% \mathrm{CO}_{2}$ until $30-50 \%$ confluency was reached, after which the cardiomyocytes were transfected with either $8 \mu \mathrm{l}$ miR-155 analogue or inhibitors using lipofectamine, followed by incubation for $24 \mathrm{~h}$ in serum-free medium. Cells were then stimulated with $1 \times 10^{-7} \mathrm{mmol} / 1$ angiotensin II for $48 \mathrm{~h}$ in various groups. FAM fluorescence was assessed at an excitation wavelength of $480 \mathrm{~nm}$ and an emission wavelength of $520 \mathrm{~nm}$ using the LAS X Widefield Systems (Leica Microsystems GmbH, Wetzlar, Germany).

Experimental groups. The cardiomyocytes were divided into six groups, as follows: i) Untreated control cells, subjected to no transfection or chemical regents; ii) treated with $1 \times 10^{-7} \mathrm{mmol} / 1$ angiotensin (Ang II) only; iii) transfected with $80 \mathrm{nmol} / \mathrm{l} \mathrm{miR}-155$ analogue; iv) transfected with $80 \mathrm{nmol} / 1 \mathrm{miR}-155$ inhibitors; v) 80 transfected with nmol/l miR-155 analogue and treated with $1 \times 10^{-7} \mathrm{mmol} / \mathrm{l}$ AngII; and vi) transfected with $80 \mathrm{nmol} / 1 \mathrm{miR}-155$ inhibitors and treated with $1 \times 10^{-7} \mathrm{mmol} / 1 \mathrm{AngII}$. The concentration of AngII was determined in accordance with a previous study by Zheng et al (11). A previous study by Cheng et al (12) was used to determine the concentration of miR-155 analogue and miR-155 inhibitor used.
Cell area measurement. Cardiomyocytes were fixed with $4 \%$ paraformaldehyde for $15 \mathrm{~min}$ and imaged using phase contrast microscopy. The LAS X Widefield Systems was used to count cardiomyocytes and measure the diameter of single cells. For each group, 10 images were captured under different perimeters, and 20 cardiomyocyetes were counted within each perimeter. ImageJ 1.45 software (National Institutes of Health, Bethesda, MA, USA) was used to calculate the number of cardiomyocetes and measure the average surface area. Three replicates were used in each experimental group.

Intracellular calcium $\left(\left[\mathrm{Ca}^{2+}\right] \mathrm{i}\right)$ measurements. Calcineurin and intracellular $\mathrm{Ca}^{2+}$ concentration are focal to the development of angiotensin II-induced cardiac hypertrophy $(13,14)$. To determine intracellular calcium levels, $5 \mu \mathrm{mol} / 1$ Fura-2/AM (Biotium, Inc., Hayward, CA, USA) solution was added to the cell suspension in all groups for $30 \mathrm{~min}$ at $37^{\circ} \mathrm{C}$. Cells were then washed twice with Hank's buffered salt solution supplemented with $0.2 \%$ bovine serum albumin (Roche Diagnostics- Basel, Switzerland). Measurements were then obtained with an excitation wavelength of $340 \mathrm{~nm}$ and an emission wavelength of $510 \mathrm{~nm}$ using a fluorescent spectrophotometer (Lengguang, Shanghai, China).

Reverse transcription-polymerase chain reaction (RT-PCR) and quantitative (PCR). To detect atrial natriuretic peptide (ANP), myosin heavy chain- $\beta$ ( $\beta$-MHC), calcineurin- $\beta$ $(\mathrm{CaN}-\beta), \mathrm{AGTR}_{1}, \mathrm{miR}-155$ and Rnu6 expression, cDNA was synthesized using Platinum SYBR Green qPCR SuperMix-UDG, according to the manufacturer's protocol. The RT-PCR primer sets are reported in Table I. Quantitative Stem-Loop RT-qPCR was used to detect the expression levels of miR-155, according to a previous study (15). These primers are listed in Table II. The RT-PCR cycling conditions were as follows: $94^{\circ} \mathrm{C}$ for $3 \mathrm{~min} ; 35$ cycles at $94^{\circ} \mathrm{C}$ for $30 \mathrm{sec}$; and $72^{\circ} \mathrm{C}$ for $1 \mathrm{~min}$. Amplifications were performed in an ABI 7300 Real Time PCR System, under the following thermal cycling conditions: $50^{\circ} \mathrm{C}$ for $2 \mathrm{~min}, 95^{\circ} \mathrm{C}$ for $2 \mathrm{~min}$, followed by 40 cycles at $95^{\circ} \mathrm{C}$ for $15 \mathrm{sec}$ and $60^{\circ} \mathrm{C}$ for $30 \mathrm{sec}$, and finally $20^{\circ} \mathrm{C}$ for $2 \mathrm{~min}$. miR-155 expression levels were normalized to Rnu6 expression levels. Expression ratios were calculated by the $2^{-\Delta \Delta \mathrm{Cq}}$ method (16).

Western blot analysis. Total protein was obtained from the rat cardiomyocytes using radioimmunoprecipitation assay lysis buffer (Boster Biological Technology, Co., Ltd.). Protein samples (30 $\mu \mathrm{g}$ total protein) were separated by $10 \%$ SDS-PAGE, transferred to polyvinylidene fluoride membranes, and blocked with $5 \%$ skimmed milk for $1 \mathrm{~h}$. The membranes were then incubated overnight at $4^{\circ} \mathrm{C}$ with rabbit polyclonal antibodies against AGTR $_{1}$, GAPDH, CaN- $\beta$, and NFAT-4 (1:500 dilution). After washing the membranes with Tris-buffered saline supplemented with 0.05\% Tween-20 (Boster Biological Technology, Co., Ltd.), the membranes were incubated with HRP-conjugated goat anti-rabbit IgG (1:15,000 dilution) at room temperature for $1 \mathrm{~h}$. The protein bands were visualized using enhanced chemiluminescence, after which images of the gels were captured and protein band intensities were quantified using Quantity One software, version 4.4 (Bio-Rad Laboratories, Inc., Hercules, CA, USA). 
Table I. Reverse transcription-polymerase chain reaction primers.

\begin{tabular}{llcc}
\hline Gene & Primers $\left(5^{\prime}-3^{\prime}\right)$ & Sequence length $(\mathrm{bp})$ & Melting temperature $\left({ }^{\circ} \mathrm{C}\right)$ \\
\hline$\beta-\mathrm{MHC}$ & & 264 & 53 \\
$\mathrm{~F}$ & AGGAAGAACCTACTGCGACTG & & \\
$\mathrm{R}$ & CATCCTTAGGGTTGGGTAGCAC & 412 & 53 \\
$\mathrm{ANP}$ & & & \\
$\mathrm{F}$ & GGCTCCTTCTCCATCACC & 198 & 53 \\
$\mathrm{R}$ & CTCCAATCCTGTCAATCCTAC & & \\
$\mathrm{CaN}-\beta$ & & & 58 \\
$\mathrm{~F}$ & CCATCTGGT AAAAGAAGGTCG & 496 & \\
$\mathrm{R}$ & AGGTATCGTGTATTAGCAGGTGA & & \\
GAPDH & & & \\
$\mathrm{F}$ & CAAGGTCATCCATGACAACTTTG & & \\
$\mathrm{R}$ & GTCCACCACCCTGTTGCTGTAG & &
\end{tabular}

bp, base pairs; F, forward; R, reverse; $\beta$-MHC, myosin heavy chain- $\beta$; ANP, atrial natriuretic peptide; CaN- $\beta$, calcineurin- $\beta$; GAPDH, glyceraldehyde-3-phosphate dehydrogenase.

Table II. Rnu 6 and miR-155 primers.

\begin{tabular}{lll}
\hline Gene & Reverse transcription-PCR primers (5'-3') & Quantitative PCR primers (5'-3') \\
\hline Rnu 6 & CGCTTCACGAATTTCCGTGTCAT & F: CTCGCTTCGGCAGCACA \\
& & R: AACGCTTCACGAATTTGCGT \\
M-miR-155-5p & CTCAACTGGTGTCGTGGAGTCG & F:ACACTCCAGCTGGGTTAATGCTAATTGTGAT \\
& GCAATTCAGTTGAGACCCCTAT & R: TGGTGTCGTGGAGTCG
\end{tabular}

PCR, polymerase chain reaction; F, forward; $R$, reverse; miR, microRNA.

Statistical analysis. Data were analyzed with SPSS 13.0 software (SPSS, Inc., Chicago, IL, USA). One-way analysis of variance and Tukey's post-hoc test were used to compare data among the various groups. $\mathrm{P}<0.05$ was considered to represent a statistically significant difference. Data are presented as the mean \pm standard error of the mean.

\section{Results}

miR-155 transfection increases miR-155 expression levels. To confirm that the miR-155 analogues had been successfully transfected into the cardiomyocytes, the fluorescence of FAM-labeled miR-155 analogues was observed and miR-155 mRNA expression levels were detected by RT-PCR (Fig. 1). miR-155 analogues labeled with FAM were successfully transfected into H9C2 (2-1) cells using lipofectamine (Fig. 1A-C), and miR-155 expression was significantly increased in cells transfected with FAM-labeled analogues, as compared with the control cells $(\mathrm{P}<0.05$; Fig. 1D). Furthermore, downregulated miR-155 expression was demonstrated in the miR-155 inhibitor and angiotensin II + miR-155 inhibitor groups, as compared with the control group $(\mathrm{P}<0.05)$ In addition, the expression levels of miR-155 were significantly increased in the angiotensin II + miR-155 analogues group, as compared with the cells transfected with miR-155 analogues alone (P<0.05; Fig. 1D).
$A G T R_{1}$ mRNA and protein expression. Angiotensin II-AGTR signaling was shown to be markedly activated in cardiac hypertrophy (17). Therefore the effects of miR-155 on the mRNA and protein expression levels of $\mathrm{AGTR}_{1}$ were evaluated in the presence of angiotensin II (Fig. 2). Transfection with miR-155 analogues or inhibitors alone had no effect on the $\mathrm{AGTR}_{1}$ mRNA and protein expression levels ( $P>0.05)$, as detected by RT-PCR and immunoblotting, respectively. Angiotensin II treatment significantly increased the mRNA and protein expression leves of $\mathrm{AGTR}_{1}$, as compared with the control cells $(\mathrm{P}<0.05)$. Notably, miR-155 analogues significantly reduced the effects of angiotensin II on miR-155 expression in cardiomyocytes $(\mathrm{P}<0.05)$, but these were not restored to control levels. The mRNA and protein expression levels of AGTR were significantly increased in the angiotensin II + miR-155 inhibitor group, as compared with the angiotensin II alone group $(\mathrm{P}<0.05)$.

Myocardiocyte surface area and the mRNA expression of $\beta-M H C$ and $A N P$. Cardiac hypertrophy is characterized by an increase in the size of cardiomyocytes, and in the synthesis of ANP and $\beta$-MHC $(18,19)$. Cardiomyocytes incubated with angiotensin II, or transfected with miR-155 analogues or inhibitors and then treated with angiotensin II, had greater surface areas, as compared with control cells (Fig. 3A and B). The mRNA 

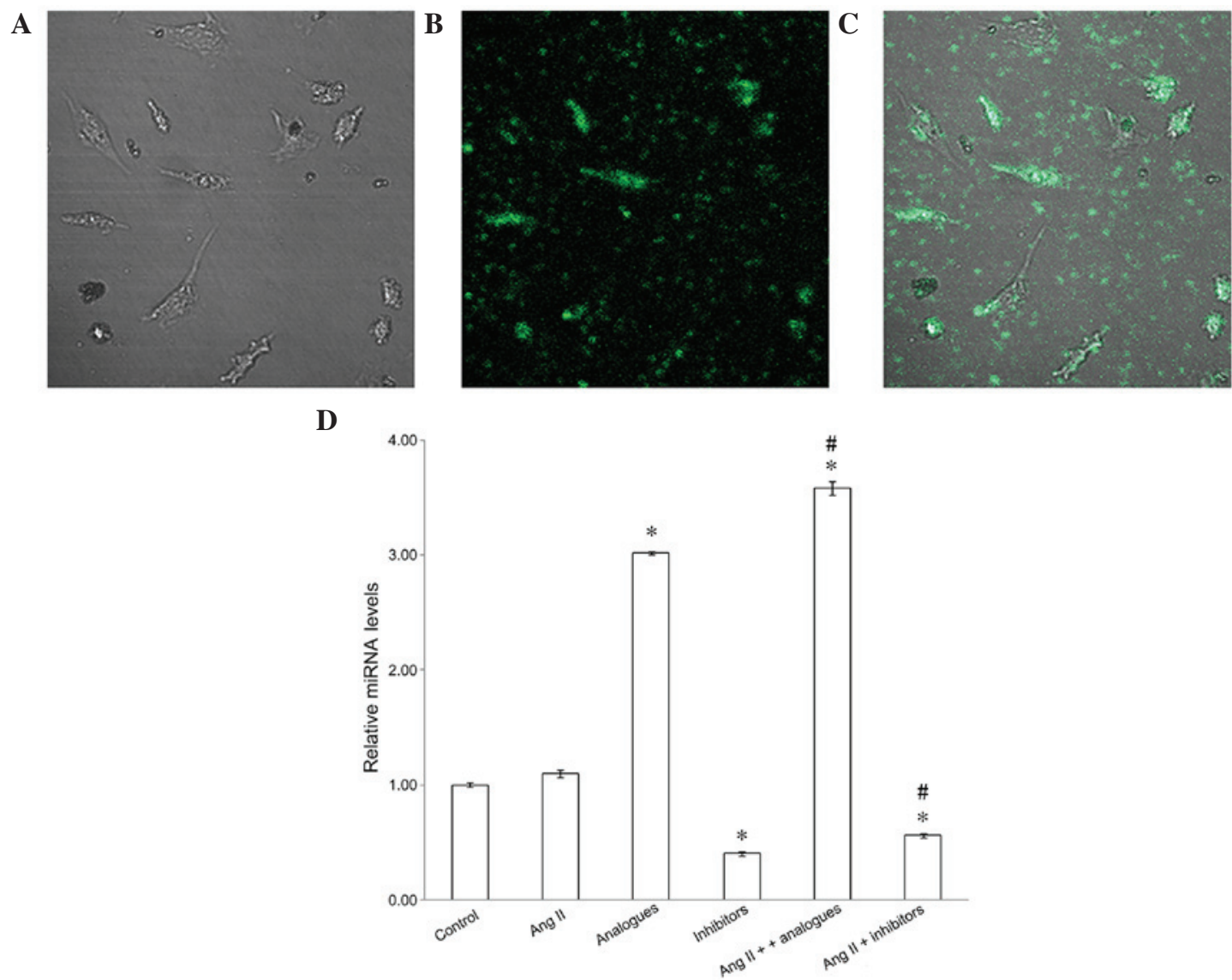

Figure 1. Changes to cellular expression levels of miR-155 following transfection with miR-155 analogue and/or inhibitor. (A-C) Immunofluorescence demonstrating cellular distribution of miR-155 analogues labeled with fluorescein (magnification, $\mathrm{x} 400$ ). (D) Graph illustrating relative miRNA expression levels following transfection with miR-155 analogue or inhibitor and/or treatment with AngII. ${ }^{*} \mathrm{P}<0.05$, vs. the control group; ${ }^{*} \mathrm{P}<0.05$, vs. the AngII group. miR-155, microRNA-155; AngII, angiotensin II.

A

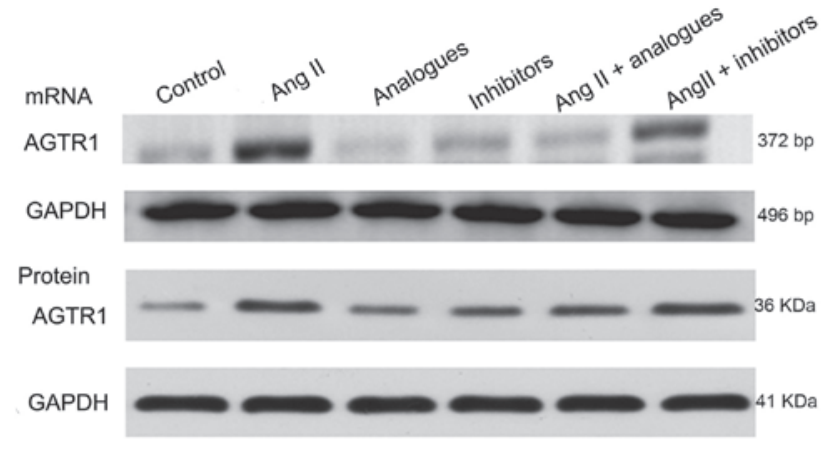

B

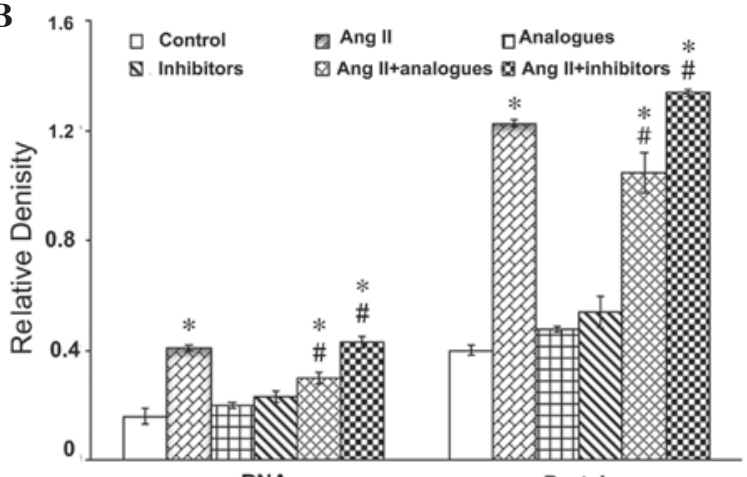

Figure 2. (A) Effects of miR-155 analogue or inhibitor on AGTR 1 mRNA and protein expression in cardiomyocytes. (B) Relative density between these groups. "P $<0.05$, vs. the control group; ${ }^{*} \mathrm{P}<0.05$, vs. the AngII group. AGTR1, angiotensin II receptor subtype 1; AngII, angiotensin II; GAPDH, glyceraldehyde-3-phosphate dehydrogenase; bp, base pairs.

expression levels of $\beta$-MHC (Fig. 4A-C) and ANP (Fig. 4B-D) were significantly increased in the angiotensin II-treated group, as compared with the control cells $(\mathrm{P}<0.05)$, whereas the mRNA expression levels of ANP and $\beta$-MHC in cells transfected with miR-155 inhibitors or analogues alone were not significantly different from the control cells $(\mathrm{P}>0.05)$. Furthermore, $\beta$-MHC and ANP levels were significantly decreased in the angiotensin II-treated, miR-155 analogue-transfected group, as compared with the angiotensin II only group ( $\mathrm{P}<0.05$; Fig. 4B).
$\left[\mathrm{Ca}^{2+}\right] \mathrm{i}, \mathrm{NFAT}-4$ and $\mathrm{CaN}-\beta$ expression. In previous studies, angiotensin II was shown to promote $\mathrm{CaN}-\beta$-mediated calcium influx and NFAT-4 translocation into the nucleus by activation of $\mathrm{CaN}-\beta$ in cardiomyocytes, resulting in upregulation of the expression of ANP and $\beta$-MHC (20). Upon angiotensin II treatment, the miR-155 analogue-transfected cells had lower intracellular calcium levels, and NFAT-4 and CaN- $\beta$ expression levels ( $\mathrm{P}<0.05$; Figs. 5-7). However, treatment of miR-155 inhibitor-transfected cells 


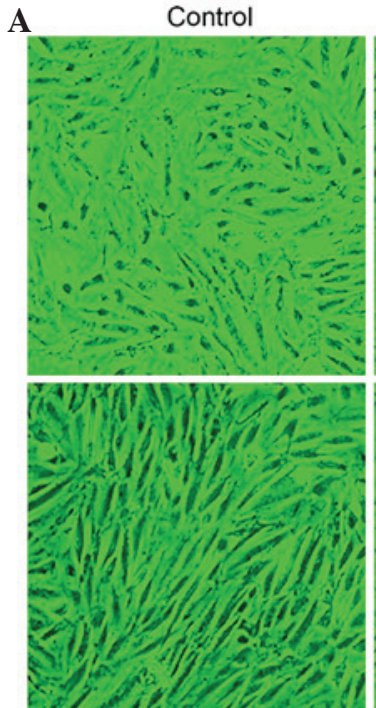

Ang II
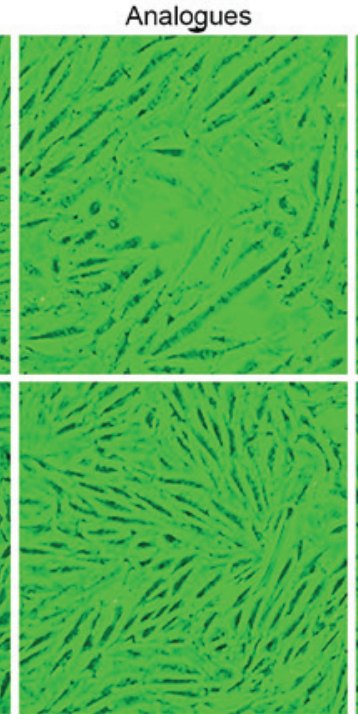

Ang II + Analogues

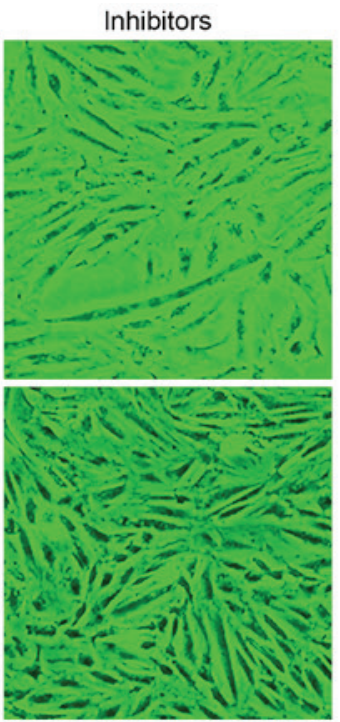

Ang II + Inhibitors

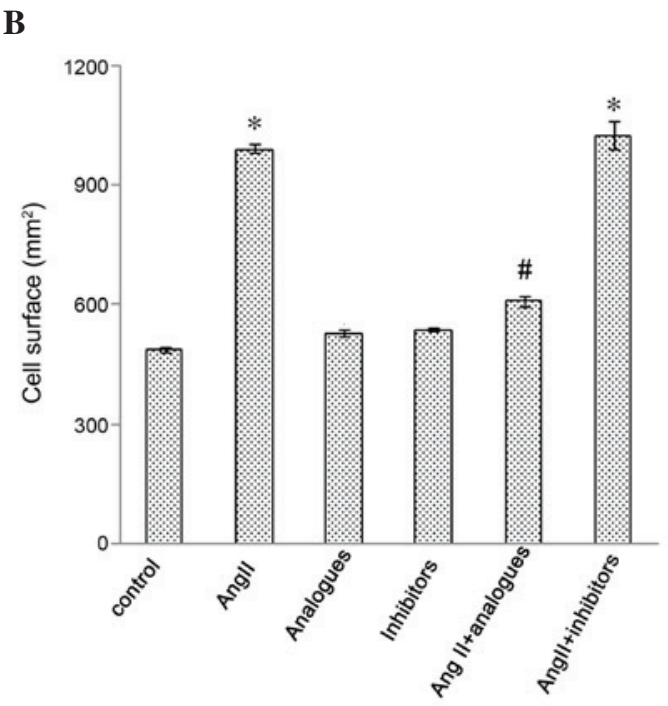

Figure 3. Changes to myocardial cell surface area observed following transfection with miR-155 analogue or inhibitor and/or treatment with AngII. (A) Micrographs of the cells (magnification, x200); (B) Cell surface area among the groups. ${ }^{*} \mathrm{P}<0.05$, vs. the control group; ${ }^{~} \mathrm{P}<0.05$, vs. the AngII group. AngII, angiotensin II.

\section{A}

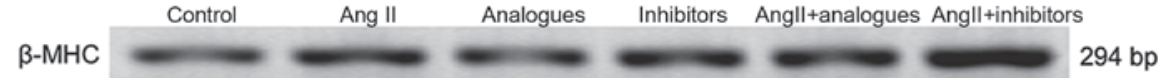

GAPDH

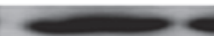

$-2000000$

$94 \mathrm{bp}$

\section{B}

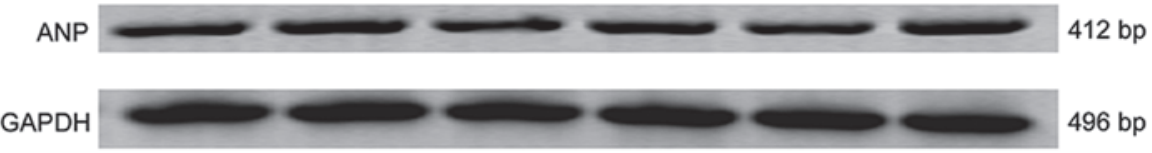

C
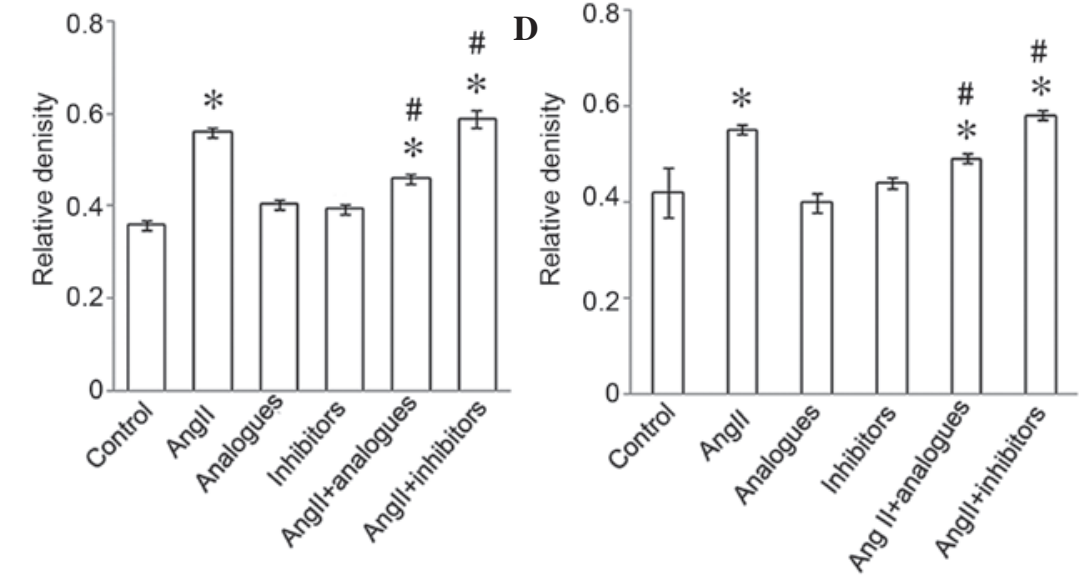

Figure 4. (A) $\beta$-MHC and (B) ANP mRNA expression levels following transfection with miR-155 analogue or inhibitor and/or treatment with AngII (C and D) Relative density of $\beta$-MHC and ANP mRNA expression. " $\mathrm{P}<0.05$, vs. the control group; ${ }^{~} \mathrm{P}<0.05$, vs. the AngII group. AngII, angiotensin II; $\beta$-MHC, myosin heavy chain- $\beta$; ANP, atrial natriuretic peptide; bp, base pairs.

with angiotensin II caused increased intracellular calcium, NFAT-4 and CaN- $\beta$ expression ( $\mathrm{P}<0.05$; Fig. 5-7).

\section{Discussion}

The angiotensin II-AGTR ${ }_{1}$ and calcineurin signal transduction pathways have vital roles in the development of myocardial hypertrophy (21). Angiotensin II has previously been reported to regulate the expression of numerous miRNAs, including miR-29b, miR-129-3p, miR-132, miR-132 and miR-212 (22). Sayed et al (23) reported in an in vivo model that numerous miRNAs are involved in the regulation of calcineurin signaling, and miR-155 was central to this cardiac hypertrophy model. Cheng et al (12) revealed that miR-155 inhibited AGTR ${ }_{1}$ 


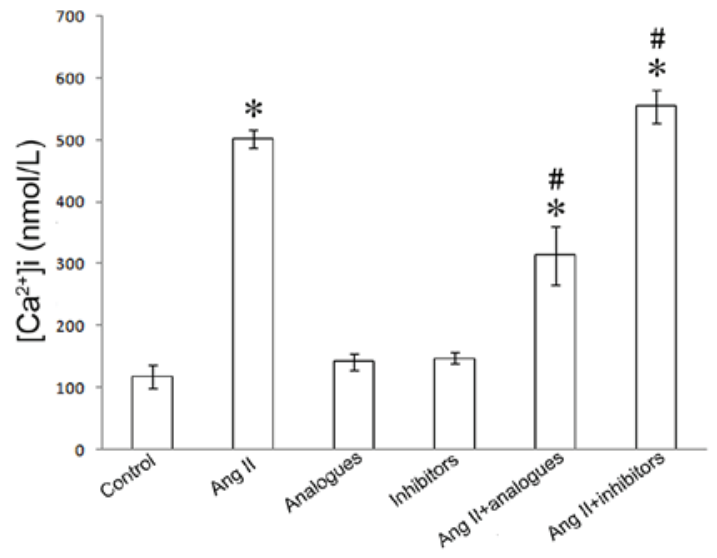

Figure 5. Intracellular calcium levels following transfection with miR-155 analogue or inhibitor and/or treatment with AngII. "P<0.05, vs. the control group; ${ }^{*} \mathrm{P}<0.05$, vs. the AngII group. AngII, angiotensin II; $\left[\mathrm{Ca}^{2+}\right] \mathrm{i}$, intracellular calcium levels.
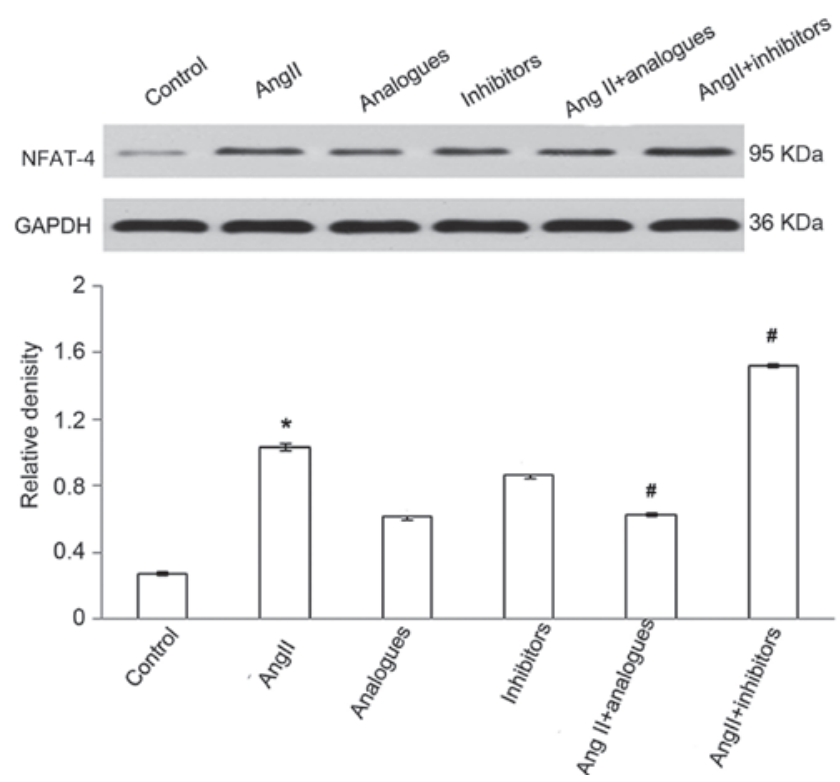

Figure 6. NFAT-4 protein expression levels following transfection with miR-155 analogue or inhibitor and/or treatment with AngII. "P<0.05, vs. the control group; ${ }^{~} \mathrm{P}<0.05$, vs. the AngII group. AngII, angiotensin II; NFAT-4, nuclear factor of activated T-cells- 4 .

expression, possibly through binding to the $3^{\prime}$ non-coding region of the $\mathrm{AGTR}_{1}$ gene, resulting in $\mathrm{AGTR}_{1}$ gene silencing.

The present study demonstrated that, compared with normally growing cardiomyocytes, miR-155 mRNA expression increased 3-4 fold upon transfection with miR-155 analogues when combined with angiotensin II treatment. However, transfection with miR-155 inhibitors had the opposite effect in cells treated with angiotensin II. Overexpression of miR-155 was able to effectively inhibit AGTR expression $_{1}$ at the mRNA and protein level in hypertrophic cardiomyocytes. When hypertrophic H9C2 (2-1) cells were incubated with miR-155 analogues, intracellular calcium concentrations were reduced, and those of CaN- $\beta$ and NFAT- 4 were upregulated. Furthermore, cell area was increased in hypertrophic rat cardiomyocytes, and $\beta$-MHC and ANP levels, which are indicative of the degree of hypertrophy, were reduced.

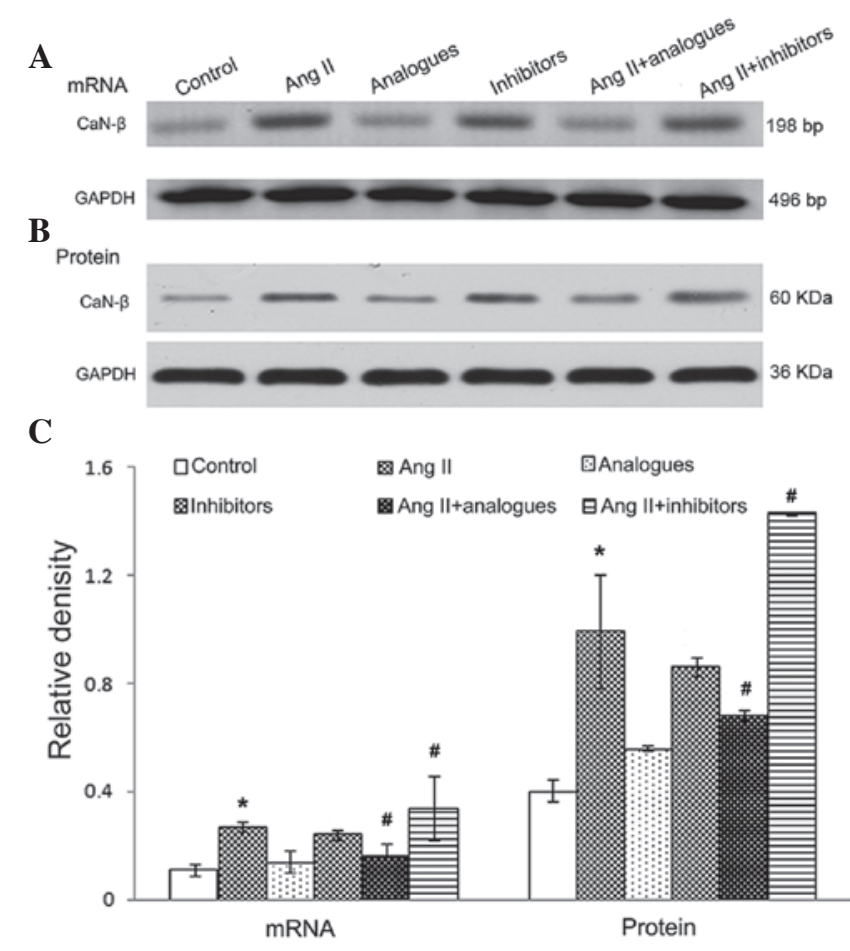

Figure 7. CaN- $\beta$ (A) mRNA and (B) protein expression levels following transfection with miR-155 analogue or inhibitor and/or treatment with AngII. (C) Relative density of between these groups. "P<0.05, vs. the control group; ${ }^{\#} \mathrm{P}<0.05$, vs. the AngII group. AngII, angiotensin II; CaN- $\beta$, calcineurin- $\beta$; GAPDH, glyceraldehyde-3-phosphate dehydrogenase; bp, base pairs.

It was therefore speculated that miR-155 may inhibit angiotensin II-induced cardiac hypertrophy by silencing the AGTR ${ }_{1}$ and the calcineurin signal transduction pathways. However, transfection with miR-155 inhibitors did not alter ANP or $\beta$-MHC levels and cell area in hypertrophic H9C2 (2-1) cells, despite an increase in $[\mathrm{Ca} 2+] \mathrm{i}, \mathrm{CaN}-\beta$ and NFAT- 4 levels.

Two online prediction tools used to determine the miRNA targets, TargetScan and PicTar, were previously reported (24). These revealed that $\mathrm{AGTR}_{1}$ may be a target of miR-155. In addition, AGTR $_{1}$ was combined with angiotensin II to enhance $\mathrm{CaN}-\beta$ (21). Myogenic enhancer factor 2, which has been reported to be involved in the regulation of $\mathrm{CaN}-\beta$, is a regulatory target of miR-155 (25). Suppressor of cytokine signaling 1 from macrophages may also be a target of miR-155 and participate in cardiac hypertrophy (8). Conversely, angiotensin II may also elevate intracellular calcium concentration via the phospholipase C-inositol trisphosphate signaling pathway (26), and increase mitogen-activated protein kinase levels to induce cardiac hypertrophy (27). These data indicate that multiple factors cause cardiac hypertrophy, including the effects of $\mathrm{AGTR}_{1}$. miR-155 may therefore represent a target at multiple sites during the development of cardiac hypertrophy induced by angiotensin II The present study solely investigated the role of miR-155 within hypertrophic cardiomyocytes, however. The calcium signaling pathway may have an important role in the development of cardiac hypertrophy, and in the apoptosis of myocardial cells (28). In the current study, miR-155 inhibitors did not attenuate hypertrophy of H9C2 (2-1) cells. It is possible that when miR-155 is inhibited, activation of the calcium signaling pathway may lead to the apoptosis of 
a proportion of myocardial cells, thereby reducing the overall levels of myocardial hypertrophy markers.

In conclusion, the results of the present study demonstrated that miR-155 overexpression effectively inhibits angiotensin II-induced myocardial hypertrophy by preventing the effects of $\mathrm{AGTR}_{1}$. As a result, intracellular free calcium and NFAT-4 nuclear translocation were reduced. Additional studies are therefore required to determine the role of miR-155 as an important target in the treatment of cardiac hypertrophy.

\section{Acknowledgements}

The present study was supported by a grant from the Municipal Science and Technology Bureau (grant no. ZD2012014).

\section{References}

1. Hill JA and Olson EN: Cardiac plasticity. N Engl J Med 358 1370-1380, 2008.

2. Abraham WT, Fonarow GC, Albert NM, Stough WG, Gheorghiade M, Greenberg BH, O'Connor CM, Sun JL, Yancy CW and Young JB; OPTIMIZE-HF Investigators and Coordinators: Predictors of in-hospital mortality in patients hospitalized for heart failure: Insights from the Organized Program to Initiate Lifesaving Treatment in Hospitalized Patients with Heart Failure (OPTIMIZE-HF). J Am Coll Cardiol 52: 347-356, 2008

3. Yancy CW, Jessup M, Bozkurt B, Butler J, Casey DE Jr, Drazner $\mathrm{MH}$, Fonarow GC, Geraci SA, Horwich T, Januzzi JL, et al: $2013 \mathrm{ACCF} / \mathrm{AHA}$ guideline for the management of heart failure: Executive summary: A report of the American College of Cardiology Foundation/American Heart Association Task Force on practice guidelines. Circulation 128: 1810-1852, 2013.

4. Savoia C, Burger D, Nishigaki N, Montezano A and Touyz RM: Angiotensin II and the vascular phenotype in hypertension. Expert Rev Mol Med 13: e11, 2011.

5. Small EM and Olson EN: Pervasive roles of microRNAs in cardiovascular biology. Nature 469: 336-342, 2011.

6. Faraoni I, Antonetti FR, Cardone J and Bonmassar E: miR-155 gene: A typical multifunctional microRNA. Biochim Biophys Acta 1792: 497-505, 2009.

7. Seok HY, Chen J, Kataoka M, Huang ZP, Ding J, Yan J, Hu X and Wang DZ: Loss of microRNA-155 protects the heart from pathological cardiac hypertrophy. Circ Res 114: 1585-1595, 2014.

8. Heymans S, Corsten MF, Verhesen W, Carai P, van Leeuwen RE, Custers K, Peters T, Hazebroek M, Stöger L, Wijnands E, et al: Macrophage microRNA-155 promotes cardiac hypertrophy and failure. Circulation 128: 1420-1432, 2013.

9. Sethupathy P, Borel C, Gagnebin M, Grant GR, Deutsch S, Elton TS, Hatzigeorgiou AG and Antonarakis SE: Human microRNA-155 on chromosome 21 differentially interacts with its polymorphic target in the AGTR1 3' untranslated region: A mechanism for functional single-nucleotide polymorphisms related to phenotypes. Am J Hum Genet 81: 405-413, 2007.

10. Marian AJ: Experimental Therapies in Hypertrophic Cardiomyopathy. J Cardiovasc Transl Res 2: 483-492, 2009.

11. Zheng L, Xu CC, Chen WD, Shen WL, Ruan CC, Zhu LM, Zhu DL, Gao PJ, et al: MicroRNA-155 regulates angiotensin II type 1 receptor expression and phenotypic differentiation in vascular adventitial fibroblasts. Biochem Biophys Res Commun 400: 483-488, 2010.
12. Cheng W, Liu T, Jiang F, Liu C, Zhao X, Gao Y, Wang H, Liu Z, et al: microRNA-155 regulates angiotensin II type 1 receptor expression in umbilical vein endothelial cells from severely pre-eclamptic pregnant women. Int J Mol Med 27: 393-399, 2011.

13. Gómez AM, Ruiz-Hurtado G, Benitah JP and Domínguez-Rodríguez $\mathrm{A}: \mathrm{Ca}(2+)$ fluxes involvement in gene expression during cardiac hypertrophy. Curr Vasc Pharmacol 11: 497-506, 2013.

14. Hogan PG, Chen L, Nardone J and Rao A: Transcriptional regulation by calcium, calcineurin, and NFAT. Genes Dev 17: 2205-2232, 2003.

15. Varkonyi-Gasic E1, Wu R, Wood M, Walton EF and Hellens RP: Protocol: A highly sensitive RT-PCR method for detection and quantification of microRNAs. Plant Methods 3: $12,2007$.

16. Livak KJ and Schmittgen TD: Analysis of relative gene expression data using real-time quantitative PCR and the 2(-Delta Delta C(T)) Method. Methods 25: 402-408, 2001.

17. Saris JJ, 't Hoen PA, Garrelds IM, Dekkers DH, den Dunnen JT, Lamers JM and Jan Danser AH: Prorenin induces intracellular signaling in cardiomyocytes independently of angiotensin II. Hypertension 48: 564-571, 2006.

18. Cavallero S, González GE, Puyó AM, Rosón MI, Pérez S, Morales C, Hertig CM, Gelpi RJ and Fernández BE: Atrial natriuretic peptide behaviour and myocyte hypertrophic profile in combined pressure and volume-induced cardiac hypertrophy. J Hypertens 25: 1940-1950, 2007.

19. Haddad F, Qin AX, Bodell PW, Zhang LY, Guo H, Giger JM and Baldwin KM: Regulation of antisense RNA expression during cardiac MHC gene switching in response to pressure overload.Am J Physiol Heart Circ Physiol 290: H2351-H2361, 2006.

20. Lunde IG, Kvaløy H, Austbø B, Christensen G and Carlson CR: Angiotensin II and norepinephrine activate specific calcineurin-dependent NFAT transcription factor isoforms in cardiomyocytes. J Appl Physiol 111: 1278-1289, 2011.

21. Marian AJ: Hypertrophic cardiomyopathy: From genetics to treatment. Eur J Clin Invest 40: 360-369, 2010.

22. Jeppesen PL, Christensen GL, Schneider M, Nossent AY, Jensen HB, Andersen DC, Eskildsen T, Gammeltoft S, Hansen JL and Sheikh SP: Angiotensin II type 1 receptor signalling regulates microRNA differentially in cardiac fibroblasts and myocytes. $\mathrm{Br}$ J Pharmacol 164: 394-404, 2011.

23. Sayed D, Hong C, Chen IY, Lypowy J and Abdellatif M: MicroRNAs play an essential role in the development of cardiac hypertrophy. Circ Res 100: 416-424, 2007.

24. Kozomara A and Griffiths-Jones S: miRBase: Annotating high confidence microRNAs using deep sequencing data. Nucleic Acids Res 42: D68-73, 2014.

25. Seok HY, Tatsuguchi M, Callis TE, He A, Pu WT and Wang DZ: miR-155 inhibits expression of the MEF2A protein to repress skeletal muscle differentiation. J Biol Chem 286: 35339-35346, 2011.

26. Rinne A and Blatter LA: Activation of NFATc1 is directly mediated by IP3 in adult cardiac myocytes. Am J Physiol Heart Circ Physiol 299: H1701-H1707, 2010.

27. Izumi Y, Kim S, Zhan Y, Namba M, Yasumoto $H$ and Iwao $H$ : Important role of angiotensin II-mediated c-Jun NH(2)-terminal kinase activation in cardiac hypertrophy in hypertensive rats. Hypertension 36: 511-516, 2000.

28. Liu Q, Wilkins BJ, Lee YJ, Ichijo H and Molkentin JD: Direct interaction and reciprocal regulation between ASK1 and calcineurin-NFAT control cardiomyocyte death and growth. Mol Cell Biol 26: 3785-3797, 2006. 